\title{
Investigando as Categorias Foucaultianas: o olhar genealógico sobre os modos de condução das condutas
}

\author{
Investigating the Foucauldian Categories: a genealogical look on the \\ modes of the conduct of conducts
}

http://dx.doi.org/10.5007/2178-4582.2013v47n1p100

Nei Antonio Nunes

Universidade do Sul de Santa Catarina, Palhoça/SC, Brasil

\begin{abstract}
Neste artigo, escrutinamos primeiramente as noções foucaultianas de acontecimento, dispositivo e regime de verdade procurando destacar sua pertinência no instrumental genealógico. Levando em consideração estas noções, buscamos explicitar as categorias de governo e governamentalidade mostrando sua relação com os processos modernos e contemporâneos de condução das condutas. Para tanto, e tomando por referência o curso "Os anormais", discutimos a transformação da tecnologia pastoral em "metodologia científica": processo de normalização individualizante que sujeita as pessoas. Em seguida, com base ainda nas pesquisas genealógicas da década de 1970, indicamos a existência de práticas de poder, de resistência e de contracondutas distintas dos processos de sujeição. Estas emergem como exercícios da liberdade e, assim, como modo possível de condução da própria conduta e da conduta dos outros. Por fim, salientamos que este artigo é fruto de uma discussão eminentemente teórica, centrada em pesquisa bibliográfica e análise conceitual.
\end{abstract}

Palavras-chave: Genealogia - Poder - Condução - Resistência - Contraconduta.
In this article we have first scrutinized the Foucauldian notions of event, device and system of truth seeking to highlight its relevance in the geanological instrumental. Considering these notions, we have tried to clarify the governement and governamentality categories showing their relationship with the modern and contemporary processes of the conduct of conducts. For that, and having the course "The abnormals" as a reference, we have discussed the transformation of pastoral technology into "scientific methodology": an individualizing standardization process subjected to people. After that, still based on the 1970's genealogical researches, we indicate the existance of practices of power, resistance and distinct counter-conducts of the subjection processes. These emerge as freedom exercises and, therefore, as a possible way of conducting the self conduct and the other's. Lastly, we would like to stress this article is the result of an eminently theoretical discussion, centered on bibliographical research and conceptual analysis.

Keywords: Genealogy - Power - Conduction Resistance - Counter-conduct.

\section{Introdução}

A consolidação do método como procedimento investigativo rigoroso na pesquisa é um traço comum aos diferentes campos de conhecimento e modelos epistemológicos. Na tradição do pensamento social, o debate em torno das metodologias tem ocupado pesquisadores dos mais diferentes matizes. Dentre os teóricos que na segunda metade do século XX se ocuparam da questão dos procedimentos investigativos em Ciências Humanas, Michel Foucault (19261984) ganha destaque pela novidade e vitalidade de suas reflexões sobre a temática. De passagem, salientamos que a discussão metodológica atraves- 
sa toda a sua obra, ou seja, está presente desde os estudos arqueológicos da década de 1960. Quanto às pesquisas do período genealógico - que revelam importantes deslocamentos em relação ao campo conceitual arqueológico -, sobressaem-se importantes categorias investigativas como as noções de acontecimento, dispositivo e regime de verdade, atualmente utilizadas no estudo de diferentes fenômenos sociais.

Nos cursos do Collège de France intitulados "Segurança, território, população" e "Nascimento da biopolítica" - ministrados em 1978 e 1979 - Foucault dá um passo além em relação, sobretudo, ao que propusera nos estudos genealógicos sobre as disciplinas, articulando a temática do poder ao que denominou como práticas de governo e/ou governamentalidade - neologismo por ele utilizado. Com isso, o pensador francês objetiva inquirir as diversas formas de condução das condutas humanas exercidas nos diferentes espaços da sociedade. Embora anterior aos cursos citados, em "Os Anormais" (1975) já aparece uma importante problematização das práticas de condução das condutas que culminam no estabelecimento de um sofisticado processo de individualização. Trata-se da discussão de tecnologias de poder que será retomada, por exemplo, nas aulas de "Segurança, território, população". Há que considerar, contudo, que apesar dos muitos pontos de convergência entre as duas pesquisas, as práticas de direção e exame de consciência são discutidas nas aulas ministradas no Collège de France em 1975, respeitando um recorte histórico diverso daquele proposto três anos depois. Em "Os anormais", o teórico prioriza a investigação dos efeitos da tecnologia pastoral no ocidente moderno e contemporâneo. Já o curso "Segurança, território, população" coteja as experiências modernas do governo dos "outros", mas introduz a análise tendo por base a distinção entre a prática da direção de consciência dos gregos e a do cristianismo na antiguidade.

Neste artigo, ao escrutinarmos as categorias genealógicas de acontecimento, dispositivo e regime de verdade, visamos enfatizar a sua pertinência aos estudos foucaultianos dos modelos ocidentais de gestão da vida humana. Levando em consideração estas noções, procuramos explicitar as categorias de governo e governamentalidade visando confrontar alguns aspectos das práticas de governo presentes nas sociedades ocidentais, enfocando as produtividades que delas decorrem: a metamorfose da tecnologia pastoral cristã de individualização em "metodologia científica". Por fim, discutimos, com base na produção foucaultianas dos anos de 1970, possibilidades de práticas de governo (como condução da própria conduta e da conduta dos demais) distintas dos processos de sujeição analisados no curso de 1975. Salientamos ainda que este artigo é fruto de uma discussão eminentemente teórica, centrada em pesquisa bibliográfica e análise conceitual.

\section{Acontecimento, dispositivo e regime de verdade: problematizações genealógicas}

É certo que o termo genealogia indica tanto os alvos foucaultianos de pesquisa a partir de 1970, quanto a presença de Nietsche (1844-1900) no 
pensamento de Foucault. Como revela o célebre artigo "Nietzsche, a genealogia, a história", a metodologia nietzschiana - em oposição às concepções teleológicas e universalistas - efetua um deslocamento no campo de análise ao propor como pesquisa a interpretação e a avaliação dos acontecimentos históricos. Isto pode ser mais bem compreendido na análise que Foucault faz dos conceitos de Herkunft e Entstehung. A seu ver, em detrimento de Ursprung (origem), Herkunft (proveniência) e Entstehung (emergência) são, na genealógica nietzschiana, recursos de análise que possibilitam, concomitantemente, inventariar, inquirir e diagnosticar os acontecimentos. Herkunft não deve ser confundido com a busca pela origem fundadora, supostamente alicerçada numa unidade universalizante. Diferentemente disso, a proveniência visa agitar o que, em termos metafísicos, se percebia como imóvel; procura fragmentar o que se considerava, do ponto de vista de diferentes consensos, unido; bem como evidenciar a heterogeneidade do que normalmente se crê em conformidade consigo mesmo, por exemplo, pelo princípio de identidade. Entstehung, por sua vez, define-se pelo ponto de surgimento dos valores e costumes. "É o princípio e a lei singular de um aparecimento", ou seja, é o campo no qual as relações de força sociais se constituem. As emergências, desta forma, viabilizariam a identificação do intrincado estado de forças que dá condições ao aparecimento dos acontecimentos históricos (FOUCAULT, 2000, p. 264-270). Nos termos de Foucault, a metodologia nietzschiana pode ser definida como análise das proveniências e história das emergências dos acontecimentos (MARTON, 2001, p. 202-204).

Mutatis mutandis, a genealogia foucaultiana também usa estas categorias da proveniência e da emergência na interpretação de acontecimentos. Pelo viés interpretativo, a genealogia interpela os acontecimentos investigando as contingências, os acidentes, os acasos, procurando pelas singularidades tangíveis, porém nem sempre detectadas pelas Ciências Humanas e Sociais ou pela Historiografia. Desta forma, sem objetivar a revelação de significados ocultos num subsolo de fundamentos últimos, a genealogia, como crítica interpretativa, procura (por meio da cartografia, do inventário e do diagnóstico dos acontecimentos) realizar uma história das interpretações. No artigo de 1971, caracterizado por uma abordagem instrumental do léxico nietzschiano, o pensador francês esclarece:

Acontecimento: é preciso entendê-lo não como uma decisão, um tratado, um reino, ou uma batalha, mas como uma relação de forças que se inverte, um poder confiscado, um vocabulário retomado e voltado contra seus utilizadores, uma dominação que se enfraquece, se amplia e se envenena e uma outra que faz sua entrada, mascarada. As forças que estão em jogo na história não obedecem nem a uma destinação nem a uma mecânica, mas ao acaso da luta. [...] Mas o verdadeiro sentido histórico reconhece que vivemos, sem referências nem coordenadas originárias, em miríades de acontecimentos perdidos (FOUCAULT, 2000, p. 272-273). 
Com as pesquisas genealógicas em curso, Foucault volta o olhar repetidas vezes ao conceito de acontecimento, dando a impressão de que procura - nos seus livros, artigos e conferências, mas também nas aulas e entrevistas - refiná-lo, aprimorá-lo, cunhá-lo novamente. Não se pode esquecer que o seu escrutínio, na genealogia, pressupõe a investigação não só das práticas discursivas, mas também daquelas consideradas não discursivas. Esta reformulação do campo analítico foi viabilizada pela introdução da noção de dispositivo. Digamos que, para além das categorias arqueológicas da episteme e da prática discursiva, ${ }^{1}$ o dispositivo procura corresponder ao anseio de ampliação do campo investigativo. ${ }^{2}$

O dispositivo procura demarcar, na pesquisa, a natureza da relação existente entre diversos elementos heterogêneos. Para tanto, são consideradas as esferas do enunciado e das práticas institucionais e sociais não discursivas, pois o dispositivo é constituído, concomitantemente, por discursos e por práticas não circunscritas a este âmbito. Isto indica, portanto, que na pesquisa ele é o "jogo" que pode ser estabelecido por diversos elementos que são, por sua vez, distintos e relacionáveis. O dispositivo, além disso, tem função estratégica e sua formação corresponde a uma urgência histórica. "Em suma, o dito e o não dito são os elementos do dispositivo. Ele é a rede que pode ser estabelecida entre estes elementos." (FOUCAULT, 1990a, p. 244).

Com o dispositivo, a genealogia procura empreender o inventário histórico-crítico dos acontecimentos por meio da detecção das práticas discursivas e não discursivas. Trata-se, com os diferentes dispositivos (o disciplinar, o

1 Como sabemos, a análise arqueológica investiga as possíveis semelhanças e diferenças entre os saberes pelo estabelecimento da episteme de uma época. Na pesquisa arqueológica, a episteme visa relacionar os diferentes saberes procurando as vinculações possíveis, bem como suas semelhanças e transformações, para além das diferenças detectadas num nível considerado mais superficial. Assim sendo, a episteme procuraria estabelecer a homogeneidade (entendida como chave explicativa) que desse conta das continuidades e das descontinuidades entre os saberes. A investigação arqueológica teria mostrado, desta forma, a existência de duas grandes descontinuidades na episteme da cultura ocidental: a Idade Clássica e a Modernidade (FOUCAULT, 1992, p. 11-13). Contudo, a episteme, central em "As palavras e as coisas", não define o campo da análise arqueológica em todos os estudos foucaultianos da década de 1960. O livro publicado em 1966 expressaria uma concepção monolítica de episteme (trata-se, sempre, de uma única episteme que define as condições de possibilidade do saber numa determinada cultura e num momento dado). Como mostra a "Arqueologia do saber", a introdução do conceito de "formação discursiva" evidenciaria o abandono dessa perspectiva monolítica. Aliás, neste livro de cunho claramente metodológico, Foucault define o saber como o "conjunto dos elementos formados de maneira regular por uma prática discursiva e indispensáveis à constituição de uma ciência." O saber é aquilo de que podemos falar em uma prática discursiva, que, por sua vez, deve ser definida como o domínio constituído pelos diferentes objetos que irão adquirir ou não um status científico. Um saber é, também, o espaço em que o sujeito pode tomar posição para falar dos objetos de que se ocupa em seu discurso. Além disso, é o campo de coordenação e de subordinação dos enunciados em que os conceitos aparecem, se definem, se aplicam e se transformam. Um saber se define por possibilidades de utilização e de apropriação oferecidas pelo discurso. Por fim, se os saberes, em determinadas configurações, podem apresentar independência em relação às ciências, o mesmo não acontece em relação às práticas discursivas, pois não existe saber sem uma prática discursiva definida, e toda prática discursiva pode definir-se pelo saber que ela forma. (FOUCAULT, 1987, p. 206-207).

2 É importante dizer, contudo, que embora a investigação arqueológica esteja circunscrita à esfera da discursividade, a genealogia não deve ser tida como uma metodologia oposta, na medida em que proporcionaria, em relação à arqueologia, uma ruptura total e intransponível. Vejamos, por exemplo, como Foucault situa a arqueologia nas pesquisas conduzidas no Collège de France em 1976. Na primeira aula de "Em Defesa da Sociedade”, o pensador dirá: “A arqueologia seria o método próprio da análise das discursividades locais, e a genealogia, a tática que faz intervir, a partir dessas discursividades locais assim descritas, os saberes dessujeitados que daí se desprendem. Isso para reconstituir o projeto de conjunto." (FOUCAULT, 1999a, p. 16). 
de sexualidade ou aqueles concernentes às governamentalidades), de trazer à tona o multifacetado campo de forças sociais no qual estas práticas surgem, ramificam-se, ligam-se, alinham-se, justapõem-se; ou, diferentemente disso, atritam e conflitam umas com as outras.

Como mostramos até aqui, fica evidenciado: (1) que o conceito de dispositivo amplia o campo analítico dos acontecimentos para além das pretensões arqueológicas; (2) que há o encadeamento da noção de acontecimento (por meio da apropriação do léxico nietzschiano) com a proposta investigativa da genealogia foucaultiana. De certa forma, o estudo denominado "Qu'est-ce que la critique? Critique et Aufklärung", no qual Foucault analisa a atualidade da crítica e sua relação com a Aufklärung, confirma e amplia o horizonte destas asserções ${ }^{3}$. Cremos que, nesta reflexão, o pensador francês discute o acontecimento num duplo movimento, o que o faz avançar na enunciação do conceito. Com isto, queremos indicar que, ao mesmo tempo em que explicita a singularidade do acontecimento, como categoria investigativa, indica a sua adequação com distintos objetos de análise, permitindo, de tal modo, melhor situá-lo como chave interpretativa do ocidente moderno e contemporâneo.

Resumidamente, em sua exposição à Société Française de Philosophie, Foucault dirá que Kant foi responsável por erigir dois modos de tratar a questão da Aufklärung e a sua relação com a atitude crítica. Com esta proposição, aponta o pensador setecentista como fundador das duas grandes tradições por meio das quais a modernidade fora problematizada. A primeira destas perspectivas ficaria circunscrita especificamente ao campo dos problemas de Teoria do Conhecimento; já a segunda ampliaria o espaço investigativo na medida em que proporia a leitura do vórtice Aufklärung e crítica pelo viés do intrincado campo das relações de poder. É nesta segunda acepção da crítica que o acontecimento entra em cena. O neologismo d’événementialisation - Événement pode ser traduzido como Acontecimento - indica, portanto, uma análise histórico-filosófica não circunscrita ao âmbito da teoria do conhecimento, e a possibilidade de estudar o fenômeno da Aufklärung (sua emergência, transformações, implicações) como constitutivo do campo das relações de poder (FOUCAULT, 1999b, p. 8). Seria um equívoco, contudo, pensarmos que a introdução do poder na trama analítica revelaria o desinteresse do genealogista pelas implicações do conhecimento nos dilemas da Ilustração. O que Foucault faz, na verdade, é reposicioná-lo, redirecioná-lo; e nesse intento, ao inclú́-lo na ordem dos saberes, evidencia a sua relação com as práticas de poder.

Bem sabemos que as implicações do nexo poder-saber são uma questão recorrente nas pesquisas genealógicas. Em "Vigiar e punir", por exemplo, a relação poder-saber é analisada em sua positividade, a saber, como capacidade produtiva disciplinar. Sobre este ponto, cabe esclarecer que as concepções de

3 Referimo-nos ao texto apresentado por Foucault no encontro realizado na Société Française de Philosophie, em maio de 1978, sob o título de "Qu'est-ce que la critique? Critique et Aufklärung”. Embora o pensador desejasse revisá-lo antes da publicação, este veio a público sem que isso pudesse acontecer. Em relação à tradução brasileira, intitulada "Iluminismo e crítica", esclarecemos que foi feita com base na tradução italiana, que traz um título diferente do original. Optamos por manter, aqui, o título em francês (FOUCAULT, 1990b). Apesar disso, as citações foram extraídas da tradução para o português (FOUCAULT 1999b). 
positividade e negatividade não são necessariamente noções morais, isto é, positivo não é sempre sinônimo de bom, nem mesmo o negativo de mau. Positivo significa, então, a produtividade do poder; já negativo é o poder que se exerce por meio de um "corte", uma "extração", uma "subtração".

As pesquisas genealógicas, assim, levam em consideração que o poder e o saber: (1) não são externos um ao outro; e (2) formam uma espiral contínua de reforço mútuo. Como explica Foucault: "Não há relação de poder sem constituição correlata de um campo de saber, nem saber que não suponha e não constitua ao mesmo tempo relações de poder." (FOUCAULT, 1993, p. 172). Contudo, na história da violência nas prisões, esta relação fica ainda circunscrita, exclusivamente, ao campo das disciplinas e aos processos de objetivação dos sujeitos. ${ }^{4}$ Entretanto, com os novos lineamentos das pesquisas genealógicas, percebe-se a presença do nexo saber-poder na investigação de outros objetos. Nessa perspectiva, Foucault esclarece:

A palavra saber indica todos os procedimentos e todos os efeitos de conhecimento que um campo específico está disposto a aceitar em um determinado momento. O termo poder estendese a toda uma série de mecanismos particulares, definíveis e definidos, capaz de determinar comportamentos ou discursos (FOUCAULT, 1999b, p. 8).

Nos termos de Foucault, problematizar a verdade significa trazer à tona o processo de formação histórica no qual ela é produzida. Para tanto, é mister fazer o seu inventário procurando diagnosticar as regras que constituem os jogos de verdade nos diferentes campos de conhecimentos e espaços sociais. Desse modo, escrutinar os jogos de verdade é procurar mostrar os "regimes" (as regras de produção da verdade, as estratégias que moldam as concepções hegemônicas, os modos de investimento nos consensos científicos e/ou políticos, etc.) forjados nas relações de poder-saber. No entanto, o teórico francês alerta que a reconstituição da teia que constitui os regimes de verdade não deve ser interpretada como indicativo de que toda e qualquer experiência humana - nos âmbitos do pensar, do agir, do fazer - seja produto de uma construção. $\mathrm{Na}$ intenção de dirimir dúvidas quanto à sua posição, explica:

Há jogos de verdade nos quais a verdade é uma construção e outros em que ela não o é. É possível haver, por exemplo, um jogo de verdade que consiste em descrever as coisas dessa ou daquela maneira: aquele que faz uma descrição antropológica de uma sociedade não faz uma construção, mas uma descrição que tem por sua vez um certo número de regras, historicamente mutantes, de forma que é possível dizer até certo ponto, que se trata de uma construção em relação a uma outra descrição. Isso

$4 \quad$ A genealogia das tecnologias disciplinares analisa as condições pelas quais o homem moderno constitui a sua identidade, seus valores e, assim, seus modos de ser e agir, dentro de sofisticados processos institucionais nos quais ele é feito, por assim dizer, como objeto de saberes e práticas institucionais de poder. Trata-se, em "Vigiar e punir", de trazer à tona o processo de constituição da verdade destas tecnologias objetivantes que incidem sobre o homem moderno (FOUCAULT, 1993, p. 26-27). 
não significa que não se está diante de nada e que tudo é fruto da cabeça de alguém (FOUCAULT, 2004, p. 283).

Como indicamos, no seu desenvolvimento, os estudos foucaultianos não ficam circunscritos ao espectro do poder como disciplina institucional, pois a problematização genealógica ganhará novos contornos. Prova disso, a relação entre verdade, poder e sujeito deixará de ser pensada exclusivamente pelo viés das práticas de objetivação. Isto viabilizará, por exemplo, a abordagem da noção de governo e, assim, a discussão de novos domínios (epistemológicos, políticos e éticos) de condução da vida humana.

\section{Os três domínios de análise e as noções de governo e governamentalidade}

Num olhar retrospectivo sobre a trajetória teórica que empreendeu até o momento, Foucault declara, no artigo "O sujeito e o poder", de 1982, que o seu objetivo fora sempre o de investigar a questão da subjetividade, e não o fenômeno do poder. Para tanto, procurou "criar uma história dos diferentes modos pelos quais, em nossa cultura, os seres humanos tornaram-se sujeitos." (FOUCAULT, 1995, p. 231). O percurso traçado pelos três domínios investigativos da genealogia do sujeito constitui, ao final, uma ontologia histórica de nós mesmos. Primeiro, em relação à verdade (constituição do sujeito do saber); segundo, em relação ao campo do poder (constituição do sujeito de ação sobre os outros); por fim, em relação à ética (constituição de agentes morais).

A ontologia histórica de nós mesmos é também denominada pelo pensador francês como uma ontologia histórica do presente. Nela, a vinculação entre os três eixos distintos proporciona, por meio da problematização permanente da subjetividade, a crítica sobre nossa experiência constituída historicamente. Diga-se de passagem, a interpretação foucaultiana de Nietzsche (e também de Kant) subsidia a genealogia do sujeito que, ao perpassar os âmbitos da verdade, poder e ética, faz o inventário e o diagnóstico dos acontecimentos decisivos, na transitoriedade entre o moderno e o contemporâneo, à constituição daquilo que hoje somos (como indivíduos, cidadãos, profissionais, gestores, membros de corporações, etc.).

O verbete "Michel Foucault", escrito pelo teórico francês para o "Dicionário dos filósofos" - no qual utiliza o pseudônimo "Maurice Florence" - , afirma que a teoria foucaultiana ao longo de sua trajetória visou, sobretudo, empreender uma história crítica do pensamento. Neste intento, procurou realizar a história dos jogos de verdade (suas emergências) inquirindo os processos de objetivação e subjetivação pelos quais se dá a constituição do sujeito. ${ }^{5} \mathrm{O}$ in-

\footnotetext{
5 Em termos esquemáticos, podemos dizer que a "subjetivação" designa, para Foucault, um processo pelo qual se obtém a constituição de um sujeito, ou, mais exatamente, de uma subjetividade. Os "modos de subjetivação" ou "processos de subjetivação" do ser humano correspondem, na realidade, a dois tipos de análise: de um lado, os modos de objetivação que transformam os seres humanos em sujeitos - o que significa que há somente sujeitos objetivados e que os modos de subjetivação são, nesse sentido, práticas de objetivação; de outro lado, a maneira pela qual a relação consigo, por meio de um certo número de técnicas, permite constituir-se como sujeito de sua própria existência." (REVEL, 2005, p. 82).
} 
ventário das práticas individuais e sociais (modos de agir e pensar) subsidiou a análise das tecnologias de poder constitutivas do seu processo de formação. A respeito, salienta Foucault que o estudo dos processos de objetivação/subjetivação do sujeito ressignifica, na investigação, a importância e o papel das relações de poder. Assim sendo, seria preciso:

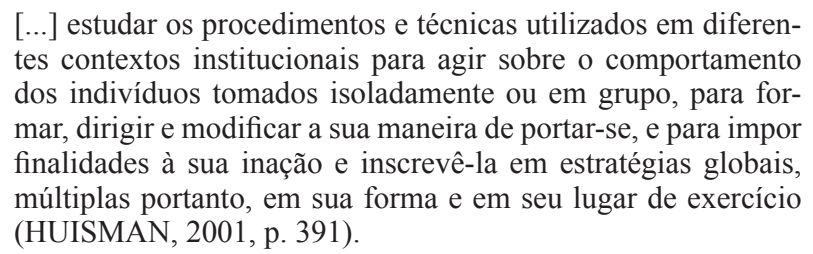

$\mathrm{Na}$ intenção de melhor explicitar o léxico foucaultiano e seus meandros, Castro (2009) oferece uma síntese bastante esclarecedora do conceito de governo. Explica o autor que a noção de governo, em Foucault, apresenta dois eixos: no primeiro, governo remete aos modos de relação entre sujeitos; já no segundo, diz respeito à relação que o sujeito estabelece consigo mesmo. No primeiro sentido, trata-se do governo como conjunto de ações sobre ações possíveis, ou seja, governar consiste em conduzir as condutas dos outros, quer se trate exclusivamente de indivíduos ou de grupos. No segundo sentido, o governo é definido como a relação que o indivíduo estabelece consigo próprio por meio, por exemplo, do domínio dos seus prazeres e desejos. Nestas duas modalidades de governo, vemos problematizado o cruzamento entre os processos de objetivação e subjetivação (CASTRO, 2009, p. 189-191). Prova disso, no bojo desta discussão ganha centralidade o tema dos limites e possibilidades da ação humana - individual e coletiva - nos diferentes espaços sociais.

É possível dizer que, em consonância com as duas definições de governo, o neologismo governamentalidade indica, sob o ponto de vista da investigação, o estudo das formas de governar. Existem dois domínios na governamentalidade. O primeiro pode ser definido pelos seguintes pontos: a) O conjunto constituído por práticas que permitem um exercício de poder que tem como alvo primordial a população; por forma central, a economia política; e, por instrumento técnico fundamental, os dispositivos de segurança; b) A linha de força que, de um lado, fez com que, no Ocidente, o governo, como modalidade de poder, ganhasse primazia sobre as demais formas, como a soberania e a disciplina e, de outro, possibilitasse o desenvolvimento de uma gama complexa e multiforme de saberes; c) A resultante do processo pelo qual o Estado de Justiça medieval transformou-se, por volta dos séculos XV e XVI, no Estado administrativo e, por fim, no Estado governamentalizado. De modo geral, a investigação desta governamentalidade leva Foucault a inquirir as formas de racionalidade por ela assumida, como também os procedimentos técnicos e os modos de instrumentalização que incorpora. Inferimos, portanto, que as governamentalidades expressam a seguinte singularidade: nunca se governa exclusivamente um Estado, território ou estrutura política, pois os governa- 
dos são sempre pessoas: coletividades, homens, indivíduos. Dirá Foucault que esta ideia de que os homens é que são governados, não é grega nem romana, pois se inscreve num outro momento e modelo de relação de poder, característico das governamentalidades inauguradas na tradição judaico-cristã (FOUCAULT, 2008, p. 143-145; 164-166).

Já a segunda acepção do termo diz respeito à confluência entre as técnicas de dominação exercidas sobre os outros e as técnicas de si. Com isto, fica claro que o estudo da governamentalidade deve abranger não só o campo da política, mas também o tema ético da relação que o sujeito estabelece consigo mesmo. Assim sendo, localizamos, no cruzamento entre as formas históricas de governo dos outros e de si mesmo, a problematização da ação humana como um ethos ético-político, a ser vivenciado, por exemplo, como "cuidado de si".

Vejamos, agora, com base nas considerações sobre os efeitos individualizantes da tecnologia pastoral cristã na modernidade e na contemporaneidade apresentados em "Os anormais" - a emergência histórica de uma "tecnologia científica" de condução das condutas do "outro", isto é, de governo dos "outros".

\section{Um olhar sobre a condução das condutas do "outro"}

Ao longo de sua trajetória intelectual, Foucault nunca perdeu de vista os dispositivos de exclusão e de controle (de sujeição do "outro") que incidem sobre os sujeitos nos diversos espaços sociais e, assim, nas mais diferentes instituições. Basta lembrar suas análises dos efeitos cerceadores da prática do internamento, discutidos em "História da loucura", ou das restrições impostas, por meio do esquadrinhamento dos espaços urbanos, como medida de assepsia social, detalhadas em "Vigiar e punir". Contudo, a articulação entre as categorias acima explicitadas sugere a possibilidade da detecção de outras configurações das técnicas de condução das condutas em múltiplos espaços da ação humana. Ressaltamos que, embora o curso de 1975 não contemple significativamente o debate metodológico sobre as categorias de governo e governamentalidade (desenvolvido, como vimos, na segunda metade da década de 1970), há elementos relevantes nessas aulas no que tange à emergência histórica de tecnologias individualizantes de condução das condutas humanas.

Em "Os anormais", Foucault empreende uma genealogia das tecnologias modernas de normalização pela análise da constituição histórica da categoria de "indivíduo perigoso". Assim sendo, a genealogia do "sujeito perigoso" traz à tona as seguintes categorias de "anormais": a) monstro humano (que remete a inadequação às leis da natureza e às normas da sociedade); b) incorrigíveis (objeto do controle dos dispositivos de correção do corpo); c) onanista (alvo, desde o século XVIII, de toda uma campanha que visa disciplinar a família moderna). A concepção de "monstro humano", tal qual se configura na modernidade, pressupõe um critério de normalização que condena o que define como "anormal" antes mesmo ou na ausência de qualquer ato considerado desviante e/ou criminoso. 
Nessa pesquisa, o teórico francês investiga as matrizes teológicas, políticas e médicas próprias do regime de verdade que dá condições ao aparecimento da noção moderna de "anormal". Esse estudo revela que a atmosfera cientificista do século XIX não anula - aliás, reforça! - os laços entre os dispositivos de poder-saber sobre o sexo e a tecnologia confessional. Por exemplo, na aula de 19 de fevereiro, Foucault discute a noção de anomalia e revela como esta se liga, durante o século XIX, à ideia de distúrbio sexual. O que acontece ao longo da modernidade - dirá Foucault - é a alteração e deslocamento de um conjunto de práticas que, na Idade Média, se limitavam à condição de aparatos eminentemente religiosos. Não se pode esquecer que a emergência do dispositivo de sexualidade, discutida em "História da sexualidade 1: A vontade de saber" (1976), mostra a transformação, na modernidade, da prática religiosa da confissão em "metodologia científica"; isto é, numa sofisticada tecnologia de condução das condutas que incide sobre os sujeitos nos mais diferentes espaços sociais.

Explicando melhor, a partir da Idade Média, as sociedades ocidentais fizeram da confissão um dos rituais mais importantes para a produção de verdade sobre os sujeitos, passando a ter um papel central na ordem dos poderes civis e religiosos. Entretanto, no século XIX, foi o discurso científico que se utilizou estrategicamente da prática da confissão, construindo com o seu auxílio, um imenso aparelho para produzir e extrair a verdade sobre o sexo. Os processos de consolidação e transformação da confissão religiosa são analisados não somente na aula ministrada no Collège de France, em 19 de fevereiro de 1975, mas também na entrevista concedida à J. François e J. de Wit, em 22 de maio de 1981, intitulada "Entrevista com Michel Foucault" (FOUCAULT, 1999c, p. 300-312). O livro "A vontade de saber", por sua vez, oferece uma apresentação esquemática da tecnologia da confissão (FOUCAULT, 1988, p. 64-66). De modo geral, o "dispositivo-confissão" pode ser entendido como "todos estes procedimentos pelos quais se incita o sujeito a produzir sobre sua sexualidade um discurso de verdade que é capaz de ter efeitos sobre o próprio sujeito" (FOUCAULT, 1990a, p. 264).

Todavia, na Idade Média, o sacramento da penitência vai se desenvolver tendo em conta não somente a confissão, mas também a direção de consciência. Por sua eficácia e função estratégica, a direção de consciência vai paulatinamente se sobrepondo à prática da confissão. O penitente, o fiel, o crente, o religioso devem relatar, ao diretor de consciência, a sua vida em detalhes e submeterem-se ao seu exame. Já o diretor de consciência é aquele a quem deve ser comunicado o que se passa na interioridade do crente. Sobre a dinâmica dessa prática individualizante de condução da conduta do "outro", Foucault explica: "Duplo fechamento, duplo filtro discursivo, no interior do qual todos os comportamentos, todas as condutas, todas as relações com o outro, todos os pensamentos também, todos os prazeres, todas as paixões [...] devem ser filtrados" (FOUCAULT, 2001, p. 232). 
O exame de consciência, por sua vez, motiva uma hermenêutica do sujeito ${ }^{6}$. Por seu intermédio, é realizado, na transitoriedade entre o período medieval e o moderno, um escrutínio da interioridade do indivíduo: dos seus desejos, dos prazeres do corpo, de suas excitações e dos seus pensamentos. Não se trata de identificar o corpo, como fará a teologia medieval, unicamente como o princípio do pecado. Agora, a sua "culpabilização" integral (corpo = espaço de distúrbio carnal) transforma-o num campo de intervenção e objeto do conhecimento.

De modo esquemático, é possível dizer que, desde a Idade Média, dois preceitos compõem esse dispositivo: 1) O exame deve permanecer ao longo de toda a vida, deve abranger a totalidade da existência da pessoa. A direção de consciência (e a confissão) objetiva, então, "fazer a totalidade da existência passar pelo filtro do exame, da análise, do discurso."; 2) O exame é colhido numa relação de poder, na qual se deve contar tudo - exclusivamente - ao diretor de consciência: "Deve-se contar tudo, mas somente aqui e a ele. Só se deve contar no confessionário, no âmbito do ato da penitência ou do procedimento de direção de consciência." (FOUCAULT, 2001, p.256). É importante frisar que a secularização dessa tecnologia pastoral não exclui a sua presença e eficácia nas instituições religiosas modernas

Em consonância com o que indica o curso de 1975, em "Segurança, território, população" Foucault assim sintetiza os traços centrais do "governo das almas" (leia-se: condução religiosa das condutas), promovido pelo poder pastoral cristão: na experiência cristã, a direção de consciência nem sempre é voluntária. Por exemplo, os monges não podiam optar por ter ou não ter diretores de consciência. Segundo, a direção de consciência cristã não é circunstancial, mas absolutamente permanente. A pessoa é dirigida sobre todos os aspectos da vida, durante toda a sua existência. Terceiro, o exame de consciência, como parte dos instrumentos da direção de consciência, não terá a função de assegurar ao indivíduo o controle de si. Diferentemente disso, o exame deve promover uma relação de dependência entre o diretor (que age como uma espécie de filtro da verdade formada, produzida, enunciada) e aquele que examina a sua própria consciência (FOUCAULT, 2008, p. 242).

Por meio desse jogo próprio à lógica pastoral do cristianismo, emerge uma nova modalidade de governo não encontrada, por exemplo, nas sociedades gregas e romanas da antiguidade. O crivo do diretor de consciência, a revelação da interioridade do crente e as prescrições que deve seguir para alcançar a salvação, fazem parte da ascese necessária à concepção de indivíduo forjada

\footnotetext{
6 Não nos esqueçamos de que a noção de exame é discutida em "Vigiar e punir" publicado em 1975, mesmo ano em que as aulas do curso "Os anormais" acontecem. Na "História da violência nas prisões" o exame é peça-chave da tecnologia disciplinar, presente em diferentes instituições modernas. É ele quem faz a junção das técnicas da vigilância hierarquizada com as técnicas da sanção normalizadora. Conforme "Vigiar e punir", o exame dá condições para que a vigilância qualifique, classifique e puna com a maior eficiência: "O exame combina as técnicas da hierarquia, que vigia, e as da sanção, que normaliza. É um controle normalizante, uma vigilância que permite qualificar, classificar e punir. Estabelece sobre os indivíduos uma visibilidade através da qual eles são diferenciados e sancionados." (FOUCAULT, 1993, p. 164). De modo geral, o exame disciplinar, assim como o exame de consciência, apresenta efeitos normalizadores. Apesar disso, suas produtividades podem corresponder a dispositivos de poder e estratégias diferentes.
} 
na instituição pastoral. A prática individualizante do "governo das almas", em toda a sua complexidade e singularidade e que repercutirá, como indica o curso de 1975, nas experiências científicas e políticas posteriores, também não está presente no monoteísmo hebreu.

O pastorado cristão constituirá um conjunto de técnicas e procedimentos individualizantes denominado como economia das almas (oikonomía psykhôn). No cristianismo, a economia das almas não diz respeito, prioritariamente, à esfera familiar, como no caso grego (ô̂kos), mas à comunidade de todos os cristãos e a cada cristão em particular? ${ }^{7}$. Todos os membros do rebanho (e cada um individualmente) são conduzidos a assumirem a identificação de "indivíduos-crentes" - processo religioso de individualização. Lembremos que é função do pastor, conforme esta doutrina religiosa, cuidar para que todas as ovelhas (omnes) e cada uma (singulatim) sejam, sem exceção, guiadas, saciadas e salvas. A relação pedagógica e hierárquica estabelecida entre o pastor e o crente (estruturada nas práticas de exame e direção de consciência) é um elemento essencial no processo de constituição da identidade individual cristã.

Dizíamos há pouco que o tema que preside as análises do curso "Os anormais" são as tecnologias modernas de normalização ou, para ser mais preciso, o processo histórico de formação, no ocidente moderno, da noção de anormalidade. A respeito, o caso de Herculine Barbin é ilustrativo de como as técnicas de direção e exame de consciência, transformadas em "metodologia científica individualizante", formam e hierarquizam "identidades" que, em diversos contextos sociais, sujeitam as vidas dos indivíduos.

O livro "Herculine Barbin: o diário de um hermafrodita", cuja apresentação foi escrita por Foucault, narra as vicissitudes de um hermafrodita no século XIX. Herculine viveu por toda vida com a identidade de mulher, recebendo a educação dada às mulheres da Europa oitocentista. Mas, quando foi descoberta sua "anormalidade" (por meio de confissão a um diretor espiritual), ela foi submetida pelos saberes da época a uma série de exames realizados por médicos, contando ainda com o respaldo jurídico e a influência da Igreja. Com base na minuciosa análise científica do seu corpo, foi decidido que "a" jovem deveria assumir a identidade de homem. Ela não se adaptou (leia-se: não se conformou) a tal processo de objetivação-subjetivação e acabou por suicidar-se. Esse belo texto, escrito pela protagonista, sugere elementos bastante significativos sobre os efeitos dos dispositivos de poder-saber (e de governo) sobre o sexo na modernidade. Foucault afirma que na Idade Média - período reconhecido como repressivo - não existiu a obrigatoriedade de um hermafro-

$7 \quad$ Contudo, a nomenclatura não é novidade na cultura antiga: "Esse conjunto de técnicas e de procedimentos que caracterizam o pastorado, os gregos, os padres gregos e, muito precisamente, São Gregório de Nazianzo já tinham dado um nome, um nome notável, já que [Gregório] chamava isso, o pastorado, de oikonomía psykhôn, isto é, economia das almas." (FOUCAULT, 2008, p. 254). Como lembra Schumpeter, no primeiro volume de "História da análise econômica", a "economia" na Grécia antiga (Oikos = casa. Nomos = lei ou regra) implicava um conhecimento prático de administração doméstica (SCHUMPETER, 1964, p. 81). Grosso modo, é o que encontramos na análise que Aristóteles faz da economia em "A política". Num sentido restrito, a "crematística" remete à acumulação de bens. Apesar disso, a noção de economia tal qual é definida no livro I de "A política", e que está em coerência com a mentalidade predominante na Grécia clássica, tem a ver com as diversas coisas de que necessita uma família para bem viver (Cf. ARISTÓTELES, 1998, p. 19-31). 
dita assumir uma única e exclusiva identidade sexual, podendo este ter "dois sexos", ou seja, não houve necessariamente a obrigação de que este assumisse um gênero (uma única identificação). Todavia, com o surgimento das teorias biológicas e médicas sobre a sexualidade, que contaram com amparo do aparato jurídico que se instalou na forma de controle administrativo nos Estados modernos, houve uma recusa radical desse dualismo do sexo hermafrodita. $\mathrm{O}$ que fez com que o hermafrodita fosse "induzido" a assumir uma única identidade sexual, isto é, o seu "verdadeiro sexo". Vale ressaltar ainda, no caso de Herculine Barbin, a exposição pública e a humilhação por ela sofrida com os minuciosos exames e com dossiê completo sobre seu corpo, descrevendo detalhadamente sua anatomia, inclusive os seus órgãos genitais (FOUCAULT, 1982). Como vemos, quando levadas ao paroxismo, essas tecnologias de governo desqualificam a autonomia e a liberdade e podem, em muitas situações, causar danos irreversíveis às vidas humanas.

Em face do exposto até aqui, podemos questionar: será que toda forma de condução das condutas do "outro" culmina na injunção de identidades que não passam, no final das contas, de sofisticados processos de sujeição humana (indivíduo-crente, sujeito anormal)? Há outros modos de conduzir a si mesmo e aos outros que não resultem em práticas que anulam a liberdade (individual e coletiva)?

Bem sabemos que as pesquisas genealógicas desenvolvidas nos anos de 1980 indicam que a governamentalidade também apresenta uma perspectiva ética (terceiro domínio da ontologia histórica de nós mesmos). O ethos proposto nessas pesquisas implica numa prática refletida da liberdade por parte do sujeito. Assim, por meio de uma "ética da estética da existência" e do "cuidado de si", ele deve procurar governar a si mesmo e aos outros nos diferentes campos de ação. No entanto, interessa-nos investigar, neste artigo, se os textos genealógicos aqui estudados - que remetem à produção foucaultiana dos anos de 1970 - indicam possibilidades de condução das condutas diversas dos processos de sujeição revelados no curso "Os anormais".

\section{Considerações finais: outras práticas de condução das condutas?}

Ainda uma palavra sobre os modos de governo que sujeitam os indivíduos e o conjunto social a partir da modernidade. Como vimos, houve diferentes movimentos de "conduta" diretamente ligados à lógica pastoral, mas não circunscritos às sociedades medievais. Nos séculos XVII e XVIII, por exemplo, a governamentalidade política retomará as funções pastorais - governo político visando à condução das condutas da população ${ }^{8}$. Nesse momento, os conflitos de conduta não são religiosos, mas do âmbito das instituições políticas.

8 Mesmo não discutindo as noções de biopoder e biopolitica neste artigo, reconhecemos sua importância como tecnologia de gestão das condutas individuais e coletivas. De passagem, indicamos que os processos de sujeição desencadeados pelo biopoder articulam uma anátono-politica dos corpos individuais com os modos de controle coletivo. A biopolitica, por sua vez, prioriza a regulação no âmbito da população. 
Outro espaço privilegiado para o desenvolvimento do pastorado na modernidade é o campo dos saberes, das instituições e das práticas médicas. Além desse âmbito de ação para as práticas pastorais, Foucault fala de formas de pastorado contemporâneas, como as práticas pastorais na antiga União Soviética: "Poderíamos falar, aliás, da pastoralização do poder na União Soviética. Burocratização do partido, não há dúvida. Pastoralização do partido[...]" (FOUCAULT, 2008, p. 265-266).

No entanto, contra essas e outras versões modernas e contemporâneas de pastorado, formam-se diferentes práticas de contraconduta, isto é, práticas que se contrapõem à sujeição promovida pelos procedimentos de condução das condutas dos outros. Em relação ao caso da União Soviética, a dissidência, as lutas políticas, expressam uma dimensão de recusa da conduta estabelecida, imposta. Vale lembrar que foram os movimentos de contraconduta que geraram, no interior da Idade Média, a crise do poder pastoral.

Recordamos que, em "A vontade de saber", Foucault dirá que onde há poder, há resistência, ou seja, para existirem relações de poder, é necessário que haja pontos de resistência que, por sua vez, fazem o papel de "adversário". A resistência é, então, o outro termo da relação e, por isso, far-se-á presente em toda a rede de poder. Assim como o poder, as resistências apresentam mobilidade e são transitórias; elas introduzem clivagens por todo o corpo social, deslocam-se, rompem unidades, criam reagrupamentos. As resistências atravessam todas as camadas sociais e as unidades individuais. São inventivas, produtivas e se distribuem estrategicamente pela espessura do corpo social (FOUCAULT, 1988, p. 91-92).

Em determinadas configurações sociais, as resistências aparecem como a possibilidade da reversão no jogo das relações de poder. Isso vale - cremos como contraposição estratégica não somente à normalização, mas também a outras práticas de poder verificadas nos diferentes âmbitos da vida. Cabe esclarecer que as resistências, ao longo das pesquisas genealógicas, continuam existindo como o outro termo do poder. Todavia, após os estudos de 1976, são abordadas muito mais como contracondutas nas "relações de governo" entre os sujeitos. Isso porque a noção foucaultiana de governamentalidade amplia o debate das relações de poder, para além da oposição entre concepção jurídica e modelo estratégico, aos jogos entre subjetivação e liberdade (GROSS, 2007, p. 112). Os novos rumos da pesquisa foucaultiana revelam que as "práticas de governo" (como conduta e contraconduta) são constituídas nos campos da verdade, do poder e da ética - os três eixos da ontologia histórica de nós mesmos.

Como sabemos, nos anos de 1970, Foucault se interessa pelo tema do comprometimento ético-político dos intelectuais, o que o leva a redefinir o seu papel nos jogos entre poder e verdade (os dois primeiros domínios da ontologia histórica do presente). Para ele, o intelectual não está fora das relações de poder e não deve ser visto como portador da "verdade" das Ciências - expressa (creem tantos epistemólogos) de modo inequívoco pela objetividade - ou ainda como a consciência e voz de todos aqueles que, em nossas sociedades, 
são explorados, excluídos e/ou discriminados. Entende o teórico francês que o novo intelectual, denominado por ele como "intelectual específico", longe está das pretensões de erigir um discurso com caráter universal e imparcial. Distante dessa pretensão, tem como compromisso ético-político inquirir o estatuto hegemônico (consensual) dos regimes de verdades nos diferentes âmbitos das relações de poder e saber nos quais está inserido. De modo geral, sua atitude crítica define-se não por uma posição exterior e neutra em relação aos discursos científicos, políticos e sociais. De modo diverso, insere-se nas relações de poder e saber, procurando perscrutar os modos de constituição da verdade (historicamente constituídos). É nesse âmbito que o intelectual pode, em diferentes configurações político-sociais, exercer o poder, a resistência e criar novas formas de "ser" e de "estar" como contraconduta".

Por fim, indicamos que as possibilidades de exercer o poder na sociedade, de resistir às formas de injunção, de subverter (transformar) as condutas, indicam modos de subjetivação nos quais os sujeitos procuram governar a si e aos outros. Assim, nos diferentes domínios da ontologia do presente, a liberdade aparece como resistência e contraconduta contra as tecnologias individualizantes e massificantes do poder e, desse modo, como condução autônoma de si mesmo e dos outros. Isso nos faz concluir que, por exemplo, a autonomia humana não se reduz às formas de individualização medievais, modernas ou contemporâneas. De modo diverso, a ontologia histórica de nós mesmos mostra a íntima relação entre as práticas da liberdade (nas quais os sujeitos interagem, afetam-se mutuamente, tocam-se, constrangem-se, resistem uns aos outros, desafiam-se, animam-se, instruem uns aos outros) e a realização de um ethos pelo qual os sujeitos procuram, ao mesmo tempo, praticar o governo e sabotar os excessos de governamentalidade. Trata-se, contudo, de um desafio, de projeto por se fazer, portanto, de uma prática de liberdade.

\section{Referências bibliográficas}

ARISTÓTELES. A politica. Trad. Roberto Leal Ferreira. 2. ed. São Paulo: Martins Fontes, 1998.

CASTRO, Edgardo. Vocabulário de Foucault. Um percurso pelos seus temas, conceitos e autores. Belo Horizonte: Autêntica Editora, 2009.

FOUCAULT, Michel. Herculine Barbin: o diário de um hermafrodita. Rio de Janeiro: Francisco Alves, 1982.

.Arqueologia do saber. 3. ed. Rio de Janeiro: Forense Universitária, 1987.

9 Gadelha dá um exemplo interessante de como é possível exercer a crítica intelectual em relação aos consensos de nossa época. Tomando como referência a área da gestão administrativa, sugere que é salutar inquirir os processos de objetivação-subjetivação presentes "nas novas tecnologias gerenciais no campo da administração (management), [nas] práticas e saberes psicológicos voltados à dinâmica e à gestão de grupos e das organizações, propaganda, publicidade, markting, branding, "literatura" de autoajuda, etc. (GADELHA, 2009, p. 151). 
.História da sexualidade 1. A vontade de saber. 7. ed. Rio de Janeiro: Graal, 1988.

. Microfísica do poder. 9. ed. Rio de Janeiro: Graal, 1990a.

Qu'est-ce que la critique? Critique et Aufklärung. Bulletin de la Société française de philosophie, v. 82, n. 2, p. 35-63, avr./juin 1990b. (Conferência proferida em 27 de maio de 1978)

.As palavras e as coisas. Uma arqueologia das ciências humanas. 6. ed. São Paulo: Martins Fontes, 1992.

.Vigiar e punir. História da violência nas prisões. 10. ed. Petrópolis: Vozes, 1993.

.O sujeito e o poder. In: RABINOW, Paul; DREYFUS, Hubert. Uma trajetória filosó-

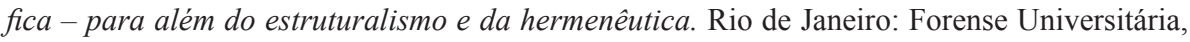
1995. p. 231-249.

Em defesa da sociedade: curso no Collège de France (1975-1976). São Paulo: Martins Fontes, 1999a. (Coleção Tópicos).

. Iluminismo e crítica. Florianópolis,1999b. p. 1-16. Mimeografado (Tradução de Selvino José Assmann).

. Michel Foucault - Problematização do sujeito: psicologia, psiquiatria e psicanálise. Rio de Janeiro: Forense Universitária, 1999c. (Coleção Ditos e Escritos, I)

. Michel Foucault - Arqueologia das ciências e história dos sistemas de pensamento. Rio de Janeiro: Forense Universitária, 2000. (Coleção Ditos e Escritos, II)

FOUCAULT, Michel. Os anormais. Curso no Collège de France (1974-1975). São Paulo: Martins Fontes, 2001.

Michel Foucault - Ética, sexualidade, política. Rio de Janeiro: Forense Universitária, 2004. (Coleção Ditos e Escritos, V)

. Segurança, território, população: curso dado no Collège de France (1977-1978). São Paulo: Martins Fontes, 2008. (Coleção Tópicos).

GADELHA, Sylvio. Biopolitica, governamentalidade e educação: introdução e conexões, a partir de Michel Foucault. Belo Horizonte: Autêntica Editora, 2009. (Coleção Educação: Experiência e Sentido).

GROSS, Frédéric. Michel Foucault. Buenos Aires: Amorrortu, 2007. (Biblioteca de Filosofia).

HUISMAN, Denis. Dicionário dos filósofos. São Paulo: Martins Fontes, 2001.

MARTON, Scarlett. Extravagâncias. Ensaios sobre a filosofia de Nietzsche. 2. ed. São Paulo: Discurso Editorial, Editora UNIJUÍ, 2001.

REVEL, Judith. Foucault conceitos essenciais. São Carlos: Claraluz, 2005. 
NUNES, Nei A. Investigando as categorias foucaultianas: o olhar genealógico sobre os modos de...

SCHUMPETER, Joseph Alois. História da análise econômica. v. 1. Rio de Janeiro: Editora Fundo de Cultura, 1964.

Recebido em: $16 / 12 / 2012$

Aceite em: 11/08/2012

Nei Antonio Nunes é doutor em Sociologia Política pela Universidade Federal de Santa Catarina. Pós-doutorando no Programa Pós-Graduação Interdisciplinar em Ciências Humanas (PPGICH) da UFSC. Professor de Ciência Política e Ética na Universidade do Sul de Santa Catarina, Campus Universitário da Grande Florianópolis. Endereço para correspondência: Rua Percy João de Borba, 83, Trindade. Florianópolis/SC, Brasil. CEP 88036-200.

E-mail: neinunes@bol.com.br 